\title{
Asunaprevir, a protease inhibitor for the treatment of hepatitis $C$ infection
}

This article was published in the following Dove Press journal:

Therapeutics and Clinical Risk Management

26 June 2014

Number of times this article has been viewed

\section{Ivan Gentile' \\ Antonio Riccardo \\ Buonomo' \\ Emanuela Zappulo' \\ Giuseppina Minei' \\ Filomena Morisco ${ }^{2}$ \\ Francesco Borrelli' \\ Nicola Coppola ${ }^{3}$ \\ Guglielmo Borgia'}

'Section of Infectious Diseases, ${ }^{2}$ Section of Gastroenterology, Department of Clinical Medicine and Surgery, University of Naples Federico II, ${ }^{3}$ Section of Infectious Diseases, Department of Mental Health and Public Medicine, Second University of Naples, Naples, Italy
Correspondence: Ivan Gentile Department of Clinical Medicine and Surgery (Ed I8), University of Naples Federico II, via S Pansini 5, I-80 I 3 I Naples, Italy

$\mathrm{Tel}+39817463178$

Fax +39817463190

Email ivan.gentile@unina.it
Abstract: According to the World Health Organization, approximately 150 million people worldwide are chronic carriers of hepatitis $\mathrm{C}$ virus (HCV). HCV infection can evolve into cirrhosis of the liver and its complications, which are ultimately responsible for more than 350,000 deaths every year. Antiviral therapy, when successful, is able to decrease the rate of progression and increase survival. Two types of therapies are currently available, ie, interferonbased therapies and interferon-free ones. The latter have several advantages in terms of safety and tolerability, and could be used even in the most advanced stages of the disease. However, their use is restricted to some viral genotypes (genotype 2 and 3) and they are expensive. Several molecules are in an advanced phase of development. This review deals with the pharmacokinetics, pharmacodynamics, tolerability, and safety of asunaprevir, an inhibitor of HCV nonstructural 3 protease. Asunaprevir exerts optimal in vitro activity particularly against HCV genotypes 1 and 4, and its pharmacokinetic profile enables twice daily administration. The drawback of asunaprevir, and of all protease inhibitors, is its low barrier to resistance. Consequently, it is used in association with other drugs to prevent resistance. Specifically, when combined with daclatasvir, an NS5A inhibitor, asunaprevir results in a very high rate of viral eradication in both treatment-naïve and treatment-experienced patients, with a sustained virological response rate of $80 \%-90 \%$. Tolerability is fair; in fact, asunaprevir is associated with a transient increase in aminotransferase levels, which is mild in most cases. In conclusion, asunaprevir is a good candidate component of interferon-free combinations and may revolutionize the treatment of chronic HCV infection in the near future.

Keywords: NS3, interferon, ribavirin, interferon-free, daclatasvir, sofosbuvir

\section{Introduction}

Hepatitis $\mathrm{C}$ virus (HCV) is an RNA virus that presently infects approximately 150 million people worldwide. ${ }^{1}$ This high number of chronic carriers is the result of two factors: exposure to unsafe blood or blood products or to blood-contaminated glass syringes or needles typical of the period between 1940 and 1980; and the high chronicity rate of subjects exposed to this virus $(54 \%-86 \%) .^{2-5}$ After the introduction of blood screening for $\mathrm{HCV}$ and of disposable syringes, the incidence of HCV infection declined, although a non-negligible risk is still associated with intravenous drug use, hemodialysis, surgery, tattooing, sexual intercourse, and endoscopy. ${ }^{6-12}$ Once chronicity is established, the disease evolves to liver cirrhosis in $15 \%-56 \%$ of cases within 20-30 years. ${ }^{5,13-19}$ Progression to cirrhosis is more frequent and rapid in patients with hepatitis B virus or human immunodeficiency virus coinfection, and in cases of alcohol abuse. ${ }^{20-22} \mathrm{HCV}$-related liver cirrhosis and its complications (ascites, jaundice, and 
hepatocellular carcinoma) cause about 350,000 deaths per year. ${ }^{1}$ Significant HCV-associated morbidity and mortality also occurs due to extrahepatic diseases, such as non-Hodgkin lymphoma and mixed cryoglobulinemia. ${ }^{23-27}$

Antiviral therapy, if successful, can interrupt progression of the disease and improve quality of life and survival. ${ }^{28-31}$ Antiviral treatment is in a transitional period from an interferon-based to an interferon-free approach. ${ }^{32,33}$ Patients with the HCV genotype 1 still need PEGylated interferon and ribavirin (PR), but this combination can be associated with a protease inhibitor (telaprevir, boceprevir, or simeprevir) or a nucleotide polymerase inhibitor (sofosbuvir). ${ }^{34-41}$ For patients with genotype 2 or 3 infection, it is possible to use PR for 24 weeks or an interferon-free therapy with sofosbuvir and ribavirin for 12 (genotype 2) or 24 (genotype 3) weeks.

Successful antiviral therapy results in lifelong viral clearance. ${ }^{42}$ The time point for assessment of viral clearance is classically 6 months after withdrawal of therapy (sustained virological response [SVR]). ${ }^{43}$ However, a 12-week time point (SVR12) has recently been demonstrated to be equivalent to the classical SVR. ${ }^{44}$ Classical PR therapy results in an SVR in $40 \%-50 \%$ of cases with genotype 1 infection and in about $80 \%$ of cases with genotype 2 or 3 infection. For genotype 1, triple therapies increase the SVR rate to about 70\%-90\%. ${ }^{45,46}$ Several host and viral factors (such as low viral load, low stage of liver fibrosis CC polymorphism of the interleukin (IL)28 gene, low homocysteine or ferritin levels, high levels of vitamin $\mathrm{D}$, and achievement of a rapid virological response) impact on the likelihood of achieving an SVR with interferon-based therapies. ${ }^{47-55}$

In this context of rapidly changing therapies, several new antivirals active against $\mathrm{HCV}$ are in clinical development. ${ }^{56-63}$ The pioneer protease inhibitors (telaprevir and boceprevir) have several limitations, namely their nonoptimal tolerability, restricted efficacy in genotype 1 disease, and a low barrier to resistance..$^{37,64}$ To overcome these drawbacks, several new (so-called second-wave or second-generation) protease inhibitors have been developed. ${ }^{60}$

This review focuses on the pharmacokinetics, pharmacodynamics, efficacy, tolerability, and viral resistance of asunaprevir, a second-wave inhibitor of HCV protease.

\section{Mechanism of action}

HCV genome has a positive polarity. This means that, once in the host cell, it can be translated into a protein without need for further transformation steps. However, this long protein must be divided by an enzyme (NS3 protease) into single proteins to be able to exert their enzymatic activity (eg, RNA-dependent RNA polymerase) or their structural role in viral particles (eg, core or E1) ${ }^{64}$ Asunaprevir targets the NS3 protease. Because NS3 protease is essential for viral replication, protease inhibitors usually exert robust antiviral activity against HCV. Protein NS3 also exerts ATPase/ helicase activity and plays a role in inhibiting the transport of interferon signaling and therefore in $\mathrm{HCV}$ viral immune escape. $^{65,66}$

In vitro, asunaprevir (formerly known as BMS-650032) exhibited good antiviral activity against replicons based on HCV genotypes 1, 4, 5, and 6 (ie, a mean 50\% effective concentration $\left[\mathrm{EC}_{50}\right]$ of $4 \mathrm{nM}, 1.2 \mathrm{nM}, 1.8 \mathrm{nM}, 1.7 \mathrm{nM}$, and $0.9 \mathrm{nM}$ against genotype $1 \mathrm{a}, 1 \mathrm{~b}, 4,5$, and 6 , respectively). ${ }^{67}$ It was less active against genotypes 2 and $3\left(\mathrm{EC}_{50} 67 \mathrm{nM}\right.$ and 1,162 nM against genotype 2 and 3, respectively). Moreover, asunaprevir is a highly selective anti-HCV agent, and is not active against viruses closely related to HCV. Asunaprevir had a good in vitro cytotoxicity profile in various human cell lines. ${ }^{67}$ Finally, when combined with other antivirals, asunaprevir exerts an additive and/or synergistic effect with interferon and with the NS5A inhibitor daclatasvir, and an additive effect with ribavirin. No antagonism was observed with the antiviral drugs tested. ${ }^{67}$ An additive/ synergistic effect was also demonstrated with recombinant interferon-lambda $1 .{ }^{68}$

\section{Pharmacokinetics}

In a preclinical study carried out in rats, mice, dogs, and monkeys, oral administered asunaprevir exhibited a high liver-to-plasma area under the curve (AUC) ratio (40 to 359 across species). ${ }^{67}$ Twenty-four hours after administration of the drug, liver concentrations were more than 100-fold higher (between 110-fold and 2,297-fold) than the $\mathrm{EC}_{50}$ obtained with a genotype 1 replicon. ${ }^{67}$

A pharmacokinetic analysis of two Phase I studies (one with single doses and one with multiple doses) carried out in naïve or experienced patients with HCV genotype 1 infection, revealed a time to achieve maximal concentration of 2-4 hours, a mean terminal half-life of 15-20 hours, and a mean oral clearance of 302-491 L/hour. ${ }^{69}$ The pharmacokinetic parameters found in healthy individuals were similar to those recorded in infected patients. ${ }^{69}$

As asunaprevir is metabolized by the liver and primarily eliminated via the feces, its exposure could be higher in patients with liver impairment. This finding prompted an evaluation of its pharmacokinetic parameters in patients with liver cirrhosis in Child-Pugh class A $(n=6), B(n=6)$, or C $(n=4)$ versus healthy subjects $(n=12) .{ }^{70}$ Subjects received 
asunaprevir at a dose of $200 \mathrm{mg}$ twice daily for a week. In patients with Child A cirrhosis, the maximum concentration and AUC were $42 \%$ and $21 \%$ lower, respectively, when compared with healthy subjects. In contrast, patients with Child B or C cirrhosis had an AUC that was 9.83-fold and 32.1-fold higher, and a maximum concentration that was 5.03-fold and 22.92-fold higher, respectively, when compared with healthy subjects. ${ }^{70}$ Based on these results, administration of asunaprevir to patients with Child B or C liver cirrhosis is not recommended. ${ }^{70}$

Another study evaluated the main pharmacokinetic parameters in subjects with renal impairment. ${ }^{71}$ In detail, 12 subjects with normal renal function (creatinine clearance $>90 \mathrm{~mL}$ per minute) and 12 patients on hemodialysis received asunaprevir at a dose of $100 \mathrm{mg}$ twice daily for 6 days and a morning dose on day 7 . The results showed only minimal and nonsignificant differences in maximum concentration and AUC between the two groups. The authors concluded that no dose adjustment is needed in patients on hemodialysis or those with renal failure. ${ }^{71}$

Finally, a study evaluated the possible drug-drug interaction between asunaprevir and the antidepressants, escitalopram and sertraline. ${ }^{72}$ Healthy fasted subjects received escitalopram $10 \mathrm{mg}$ once daily $(\mathrm{n}=15)$ or sertraline $50 \mathrm{mg}$ once daily $(\mathrm{n}=18)$ on days $1-7$ and days $25-31$. All subjects received asunaprevir $100 \mathrm{mg}$ twice daily on days 15-31. The results showed that neither escitalopram nor sertraline affected exposure to asunaprevir, and that asunaprevir did not affect exposure to escitalopram or sertraline. ${ }^{72}$

\section{Clinical trials: efficacy, safety and tolerability Asunaprevir in monotherapy}

A Phase I study evaluated the tolerability and antiviral activity of asunaprevir administered as single doses or as multiple ascending doses to patients with HCV genotype $1 .^{73}$ In detail, 24 patients were enrolled in the single dose part of the study, ie, six in each of the four dose cohorts $(10,50$, 200 , and $\leq 600 \mathrm{mg}$ of asunaprevir). In each cohort, subjects were randomly assigned to asunaprevir or placebo (ratio 5:1). Fifteen patients were enrolled in the multiple dose part of the study, ie, five for each of three dose cohorts (200, 400, and $600 \mathrm{mg}$ twice daily for 3 days). In each cohort, subjects were randomly assigned to asunaprevir or placebo (ratio 4:1). The mean age was 48 years in the single dose part of the study and 44 years in the multiple dose part. Most patients $(85 \%)$ were infected with HCV subtype 1a and the baseline mean viral load ranged between $6.21 \mathrm{log} \mathrm{IU} / \mathrm{mL}$ and $6.84 \log \mathrm{IU} / \mathrm{mL}$. In the single dose part of the study, the mean maximum decline of HCV RNA was 0.28, 0.64, 2.26, and $2.87 \log _{10} \mathrm{IU} / \mathrm{mL}$ in the $10 \mathrm{mg}, 50 \mathrm{mg}, 200 \mathrm{mg}$, and $600 \mathrm{mg}$ dose groups, respectively. In the multiple dose part of the study, the mean maximum decline of HCV RNA was 3.09, 3.57, and $2.84 \log _{10} \mathrm{IU} / \mathrm{mL}$ in the $200 \mathrm{mg}, 400 \mathrm{mg}$, and $600 \mathrm{mg}$ group, respectively. ${ }^{73}$ Adverse events in subjects who received asunaprevir were mild or moderate, and did not differ from those recorded in the placebo group. The most frequent adverse event in subjects treated with asunaprevir was headache. ${ }^{73}$

\section{Asunaprevir in combination with interferon}

The trials of asunaprevir-containing combinations (with or without interferon) are summarized in Table 1. AI447016 was a combined Phase IIa/IIb study that evaluated the efficacy of asunaprevir combined with PR. ${ }^{74,75}$ In the Phase IIa study, 47 treatment-naïve, noncirrhotic patients with HCV genotype 1 received asunaprevir at doses of $200 \mathrm{mg}$ twice daily, $600 \mathrm{mg}$ once daily, $600 \mathrm{mg}$ twice daily, or placebo (ratio 1:1:1:1) combined with PR for 48 weeks. ${ }^{74}$ The median age was between 46.5 and 52.5 years, and most patients were male and infected by HCV subtype 1a. The mean baseline viral load was between $6.4 \mathrm{IU} / \mathrm{mL}$ and $6.8 \log _{10} \mathrm{IU} / \mathrm{mL}$. Baseline features of the patients were balanced in the four arms, with the exception of the IL28B CC genotype, which was under-represented in the asunaprevir $600 \mathrm{mg}$ twice daily arm and in the placebo arm. An extended rapid virological response (ie, undetectable level of HCV RNA at weeks 4 and 12 of treatment) was achieved by $75 \%, 75 \%, 92 \%$, and $0 \%$ of patients in the following arms: asunaprevir $200 \mathrm{mg}$ twice daily, asunaprevir $600 \mathrm{mg}$ twice daily, asunaprevir $600 \mathrm{mg}$ once daily, and placebo, respectively. The corresponding figures for SVR were $83 \%, 83 \%, 92 \%$, and $46 \%$. No virological breakthrough occurred. Diarrhea, myalgia, dry skin, and depression were more frequent in the asunaprevir arm than in the interferon-only arm. Twelve weeks after a safety analysis, the dosage in the $600 \mathrm{mg}$ groups was reduced to $200 \mathrm{mg}$ due to a higher rate of aminotransferase elevation. ${ }^{74}$ Three of the 24 patients (12.5\%) in the $600 \mathrm{mg}$ asunaprevir arms had grade 3-4 elevation of alanine aminotransferase (ALT), compared with none in the placebo or $200 \mathrm{mg}$ groups. Interestingly, all cases of grade 3-4 ALT elevation resolved after a reduction of the asunaprevir dose. All grade-elevated aminotransferase and total bilirubin were more frequent on asunaprevir $600 \mathrm{mg}$ than on asunaprevir $200 \mathrm{mg}$ or interferon only. ${ }^{74}$ In detail, one patient in the $600 \mathrm{mg}$ once daily arm had 


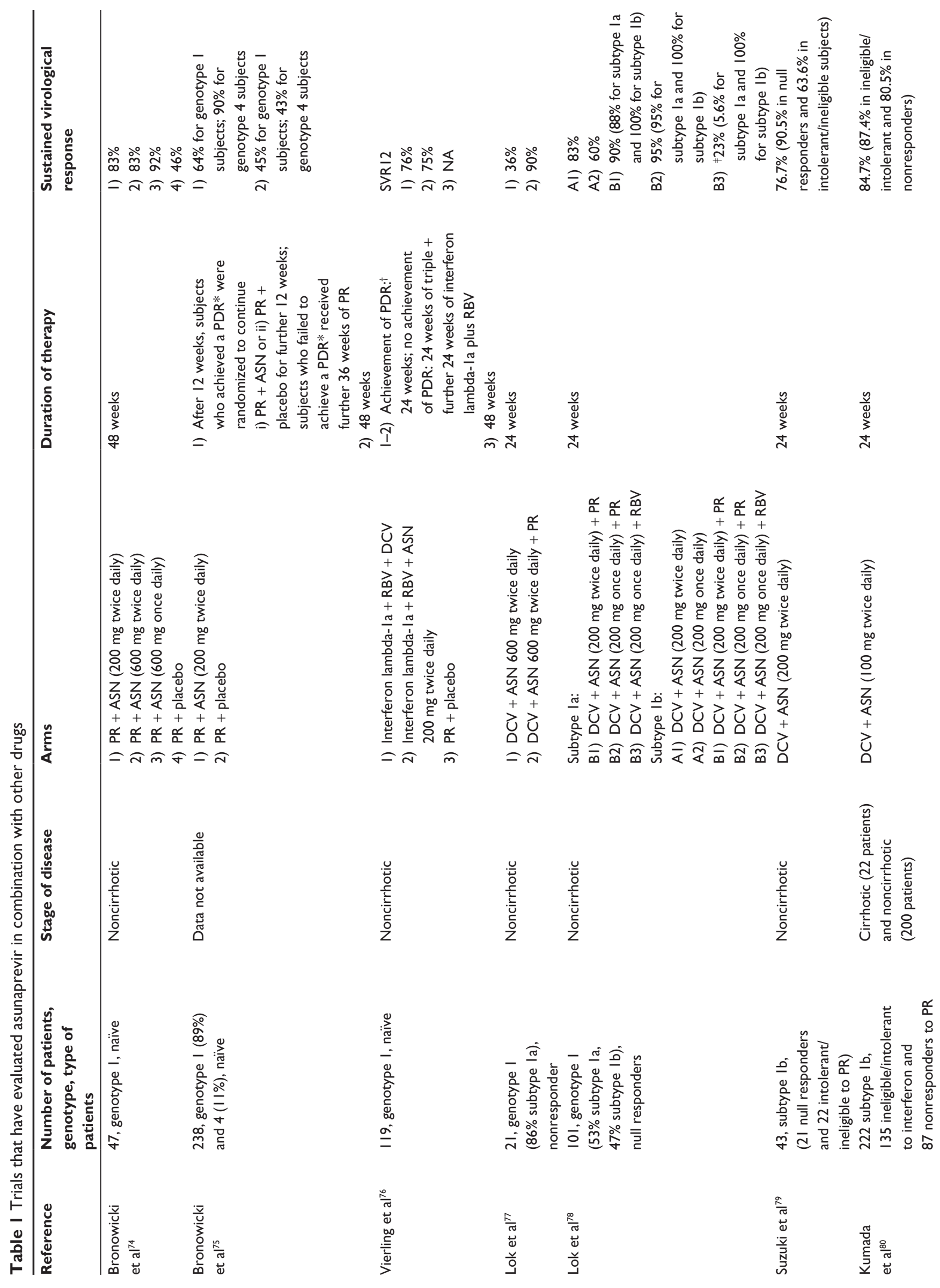



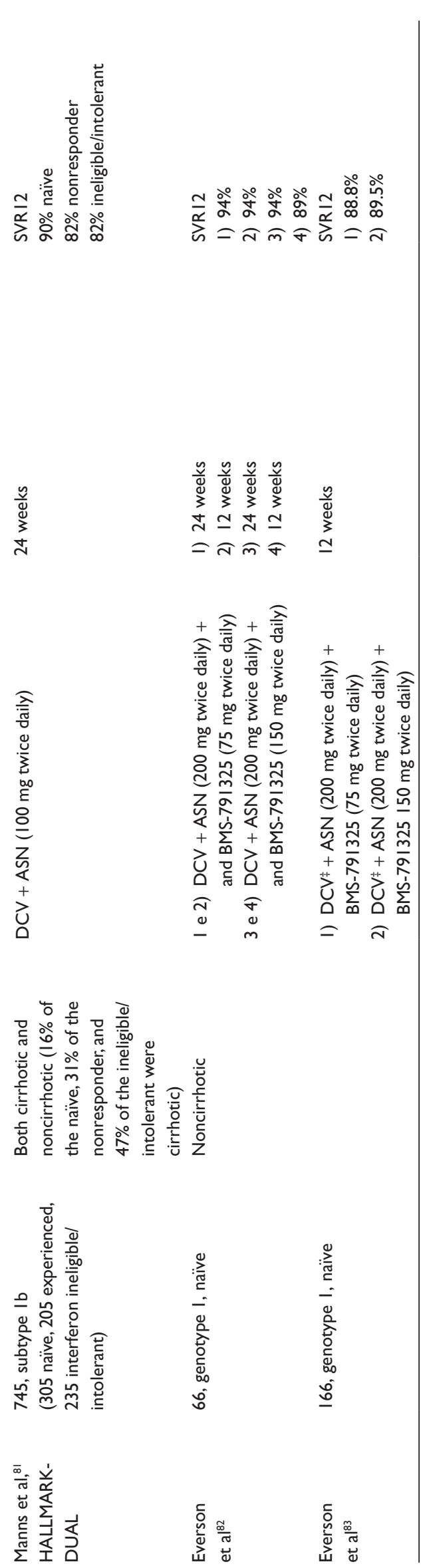

cytolytic hepatitis at week 6 , characterized by an increase of ALT to $535 \mathrm{U} / \mathrm{L}$, an increase of total bilirubin to $3.5 \mathrm{mg} / \mathrm{dL}$, and normal International Normalized Ratio and albumin. The patient discontinued asunaprevir and continued PR. This case of cytolytic hepatitis resolved at week 11 .

In the Phase IIb study, 238 patients with HCV genotype 1 or 4 were randomized (ratio 3:1) to receive asunaprevir $200 \mathrm{mg}$ twice daily or placebo. ${ }^{75}$ All patients concomitantly received PR. At week 12, patients in the active arm with a protocoldefined response (ie, HCV RNA $<25 \mathrm{IU} / \mathrm{mL}$ at week 4 and undetectable at week 10) were rerandomized 1:1 to continue either the triple treatment or dual therapy for 12 weeks. Patients with genotype 1 accounted for 89\% (212/238) of the sample. Patients who did not achieve a protocol-defined response and those in the control arm received 48 weeks of treatment. In the triple therapy arm, SVR was achieved by $64 \%$ of patients with genotype 1 ( $59 \%$ in HCV subtype $1 \mathrm{a}$ and $71 \%$ in HCV subtype $1 \mathrm{~b}$ ) and $89 \%$ of those with genotype 4 . The corresponding figures in the control arm were $45 \%$ and $43 \%$ for genotype 1 and 4, respectively. Among the genotype 1 patients who achieved a protocol-defined response $(n=133)$, SVR did not differ significantly between those randomized to 12 weeks versus 24 weeks of triple therapy (73\% versus $67 \%$, respectively). Anemia, neutropenia, and rash occurred at a similar rate in the two arms. Grade 3-4 aminotransferase elevation was found in $10 \%$ of patients in the asunaprevir arm and in $2 \%$ in the placebo arm. ${ }^{75}$

The D-LITE study (Safety Study of Pegylated Interferon Lambda Plus Single or 2 Direct Antiviral Agents With Ribavirin) evaluated the efficacy of the association of PEGylated-interferon-lambda 1a (a type of interferon with limited extrahepatic effects) $180 \mu \mathrm{g} /$ week and ribavirin (at standard doses) combined with daclatasvir $60 \mathrm{mg}$ once daily or asunaprevir $200 \mathrm{mg}$ twice daily compared with PR plus placebo in 119 treatment-naïve patients with HCV genotype $1 .{ }^{76}$ Treatment with interferon-lambda 1a lasted 24 weeks in the event of achievement of a protocol-defined response (ie, HCV RNA $<25 \mathrm{IU} / \mathrm{mL}$ at week 4 and undetectable at week 12). In the event of nonachievement of a protocol-defined response, patients received 24 additional weeks of PEGylated interferon-lambda and ribavirin. Therapy in the PR arm lasted 48 weeks. Eighty-seven percent of the 79 patients who received PEGylated interferon-lambda and ribavirin together with daclatasvir or asunaprevir achieved a protocol-defined response. Data are available for 63 patients that completed the treatment and 12 weeks of follow-up. SVR12 was achieved by $76 \%$ of patients in the daclatasvir arm and by $75 \%$ in the asunaprevir arm. Patients with genotype $1 \mathrm{~b}$ had a higher 
rate of SVR12 ( $\geq 91 \%$ ) with both antivirals than those with genotype 1a infection. ${ }^{76}$ Serious adverse events occurred in $9 \%$ of patients in the asunaprevir arm and in 3\% of patients in the daclatasvir arm. Similarly, grade 3-4 ALT and aspartate aminotransferase elevation were more frequently recorded in the asunaprevir arm (9\% and 16\%, respectively) than in the daclatasvir arm $\left(0 \%\right.$ and $5 \%$, respectively). ${ }^{76}$

\section{Asunaprevir in interferon-free combinations}

An open-label Phase IIa study evaluated the efficacy and safety of a combination of daclatasvir $60 \mathrm{mg}$ once daily plus asunaprevir $600 \mathrm{mg}$ twice daily for 24 weeks with or without PR in 21 previously nonresponder patients with HCV genotype $1 .{ }^{77}$ The median age ranged between 54 and 56.5 years, and the mean viral load was in the range of 6.6-6.8 $\log \mathrm{IU} / \mathrm{mL}$. Most patients (9/11 in the interferon-free arm and 9/10 in the interferon-containing arm) had HCV subtype 1a. At week 2, the median decline in viral load was $5.1 \log _{10} \mathrm{IU} / \mathrm{mL}$ in the interferon-free arm and $5.3 \log _{10} \mathrm{IU} / \mathrm{mL}$ in the interferoncontaining arm. Viral breakthrough occurred in six patients $(55 \%)$ in the interferon-free arm (all with HCV subtype 1a) and none in the interferon-containing arm. SVR12 was achieved by $36 \%$ of patients (2/9 with HCV subtype 1a and $2 / 2$ with HCV subtype 1 b) in the interferon-free arm and by $100 \%$ of those in the interferon-containing arm. ${ }^{77}$ No serious adverse events or discontinuations due to adverse events occurred during treatment. The most common adverse events reported were diarrhea, fatigue, headache, and nausea. Four patients in the interferon-free arm and two in the interferoncontaining arm experienced a greater than three-fold increase in ALT levels. ${ }^{77}$ In detail, the increase in ALT occurred from week 8 to 20 of treatment. The peak ALT level was $370 \mathrm{U} / \mathrm{L}$. However, in no case did the increase in ALT lead to discontinuation of treatment. ${ }^{77}$

The dramatic difference with regard to the SVR rate of the interferon-free combination daclatasvir and asunaprevir between HCV subtype 1a vs 1 b was confirmed in a randomized Phase IIa trial that evaluated the efficacy and safety of asunaprevir $200 \mathrm{mg}$ once or twice daily and daclatasvir $60 \mathrm{mg}$ once daily with or without PR for 24 weeks in 101 noncirrhotic previously null responder patients with HCV genotype $1 .^{78}$ In detail, patients with genotype $1 \mathrm{~b}$ were randomized (ratio 5:5:1:1) to one of the following arms: A1) daclatasvir and asunaprevir (administered twice daily); A2) daclatasvir and asunaprevir (administered once daily); B1) daclatasvir, asunaprevir (administered twice daily) plus PR; and B2) daclatasvir and asunaprevir (administered once daily) plus PR. Subjects with HCV genotype 1a infection were randomized 1:1 to arm $\mathrm{B} 1$ or $\mathrm{B} 2$. Once adequate activity was demonstrated in group B1, an additional group (B3) was created for patients with HCV genotype $1 \mathrm{a}$ and $1 \mathrm{~b}$ who received daclatasvir, asunaprevir twice daily, and ribavirin. Baseline characteristics were similar across the arms. The mean HCV RNA was $6 \log \mathrm{IU} / \mathrm{mL}$ and the mean age was in the range of 50-57 years. At day 7, the median decline in HCV RNA was $4.4 \mathrm{log}, 4.3 \mathrm{log}, 4.8 \mathrm{log}$, and $4.7 \mathrm{log}$ in arms A1, A2, B1, and B2, respectively. Virological breakthroughs occurred in $11 \%, 30 \%, 0 \%$, and $0 \%$ in arms A1, A2, B1, and B2, respectively. In arm B3, 10/18 patients with $\mathrm{HCV}$ subtype 1a experienced a breakthrough, and were offered rescue therapy with addition of PEGylated interferon. Given the very high rate of breakthrough, preventive addition of PEGylated interferon was offered to the other eight patients. SVR12 occurred in $78 \%, 65 \%, 95 \%$, and $95 \%$ in arms A1, A2, B1, and B2, respectively. Regarding efficacy, the authors concluded that in null responders with HCV genotype 1, twice daily asunaprevir plus daclatasvir is effective for most patients with subtype $1 \mathrm{~b}$ infection, but is largely ineffective for patients with subtype 1a. In contrast, the combination of daclatasvir, asunaprevir, and PR is effective for nearly all patients regardless of HCV subtype (1a or 1b). ${ }^{78}$ Most adverse events were mild or moderate. Grade 3-4 aminotransferase elevation occurred in four patients (two in arm A1, one in arm A2, and one in arm B3). The peak ALT value was $590 \mathrm{U} / \mathrm{L}$ (in a patient who received asunaprevir twice daily). In no case was aminotransferase elevation accompanied by symptoms of acute hepatitis or by bilirubin elevations, nor did it lead to treatment discontinuation. All cases improved with continued administration of the treatment and none were accompanied by elevation in bilirubin level. ${ }^{78}$

A Phase IIa study carried out in Japan assessed the efficacy and safety of daclatasvir $60 \mathrm{mg}$ once daily and asunaprevir $200 \mathrm{mg}$ twice daily for 24 weeks in 43 patients with HCV subtype $1 \mathrm{~b}$ (21 null responders to $\mathrm{PR}$ and 22 ineligible or intolerant to PR). ${ }^{79}$ The median age was 61 years in null responder patients and 68 years in intolerant/ineligible patients; mean HCV RNA viral load was $6.8 \log _{10} \mathrm{IU} / \mathrm{mL}$ in null responder patients and $6.6 \log _{10} \mathrm{IU} / \mathrm{mL}$ in ineligible/ intolerant patients. Overall, 33/43 patients (76.7\%) achieved an SVR. SVR was achieved by $90.5 \%$ of null responder patients and by $63.6 \%$ of intolerant/ineligible subjects. The mean decline in HCV RNA was $5.6 \log _{10} \mathrm{IU} / \mathrm{mL}$ in the null responder group and $5.4 \log _{10} \mathrm{IU} / \mathrm{mL}$ in the $\mathrm{HCV}$ RNA ineligible/intolerant group. There were no relapses or breakthroughs in the null responder group. In contrast, 
three breakthroughs and four relapses occurred in ineligible/ intolerant patients. ${ }^{79}$ Safety was good, with only four cases of grade 3-4 alanine aminotransferase elevation and three of aspartate aminotransferase elevation recorded. Two patients discontinued treatment due to hyperbilirubinemia and aminotransferase elevation. In both cases, these abnormalities normalized 4 weeks after discontinuation. ${ }^{79}$

A Japanese open-label Phase III trial evaluated the efficacy and safety of daclatasvir $60 \mathrm{mg}$ once daily plus asunaprevir $100 \mathrm{mg}$ twice daily administered for 24 weeks to 222 patients with HCV subtype 1b (135 patients ineligible/ intolerant to interferon and 87 nonresponders to PR). ${ }^{80}$ The median age was 62.5 years, and notably, $40.1 \%$ were over 65 years of age. The mean viral load was $6.6 \log _{10} \mathrm{IU} / \mathrm{mL}$, and $9.9 \%$ of patients had cirrhosis. Of the 135 ineligible/ intolerant group, 100 patients were ineligible and 35 were intolerant. The main reason for interferon ineligibility was anemia, thrombocytopenia, or neutropenia. At week 2, the mean decline in HCV RNA was $5.2 \log _{10} \mathrm{IU} / \mathrm{mL}$. Relapses occurred in $11 / 129(8.5 \%)$ patients in the ineligible/intolerant group and in six of 76 patients $(7.9 \%)$ in the nonresponder group. On intention-to-treat analysis, SVR was achieved by $87.4 \%$ of patients in the ineligible/intolerant group and by $80.5 \%$ of nonresponder patients. Interestingly, 20 of the 22 patients with cirrhosis $(90.9 \%)$ had an SVR. Similarly, IL28B polymorphism, age, baseline viral load, and gender did not affect the chance of achieving an SVR.${ }^{80}$ Safety was good. Sixteen patients had grade 3-4 ALT elevation after a median of 10 weeks of treatment. Ten of these $(4.5 \%$ of the overall sample) discontinued treatment; in two cases, there was also a grade 3-4 bilirubin elevation, but there was no case of hepatic decompensation. Notably, eight of the 10 patients who discontinued treatment due to aminotransferase elevation achieved an SVR. ${ }^{80}$

Hallmark-DUAL (ClinicalTrials.gov identifier NCT01581203), a large global Phase III trial, evaluated the combination of daclatasvir $60 \mathrm{mg}$ once daily and asunaprevir $100 \mathrm{mg}$ twice daily for 24 weeks in 745 patients with HCV genotype 1b (305 naïve, 205 previously partial or null responders, and 235 ineligible/intolerant to interferon). ${ }^{81}$ Naïve patients were randomized (2:1 ratio) to receive the active combination or placebo (after 12 weeks, all patients in the placebo arm received daclatasvir and asunaprevir). The median age was 58-72 years across the three arms. Patients with cirrhosis represented $16 \%$ of the naïve cohort, $31 \%$ of the nonresponder cohort, and $47 \%$ of the ineligible/intolerant cohort. SVR12 rates were $90 \%, 82 \%$, and $82 \%$ in naïve, nonresponder, and ineligible/intolerant patients, respectively.
The presence of liver cirrhosis, IL28 polymorphism, age, race, gender, or pretreatment viral load did not impact on SVR rate. The most common clinical adverse events were headache, fatigue, diarrhea, nausea, and asthenia, but adverse events leading to discontinuation were very rare $(1 \%-3 \%$ across the three arms). There was an increase in ALT to $>5$-fold the upper normal values in $2 \%-3 \%$ of patients and an increase in total bilirubin to $>2.5$-fold the upper normal values in $0 \%-1 \%$ of patients across the three groups. Notably, the adverse event profile was similar in the naïve patients who received the combination and in those treated with placebo.

A Phase IIa study evaluated the efficacy and safety of the interferon-free combination of daclatasvir, asunaprevir, and BMS-791325 (a non-nucleoside HCV polymerase inhibitor) in 66 treatment-naïve, noncirrhotic patients with genotype $1 .^{82}$ Patients were randomized to receive daclatasvir $60 \mathrm{mg}$ once daily, asunaprevir $200 \mathrm{mg}$ twice daily, and BMS-791325 $75 \mathrm{mg}$ twice daily for 24 weeks (group 1), $75 \mathrm{mg}$ twice daily for 12 weeks (group 2), $150 \mathrm{mg}$ twice daily for 24 weeks (group 3), or $150 \mathrm{mg}$ twice daily for 12 weeks (group 4). The overall median age was 50 years, the pretreatment viral load was $6.3 \log _{10} \mathrm{IU} / \mathrm{mL}, 74 \%$ were infected with HCV subtype 1a, and $70 \%$ had the non-CC IL28B genotype. The distributions of age, baseline viral load, rate of HCV subtype 1a, and IL28B polymorphism were comparable across the four groups. The HCV RNA level declined rapidly during treatment in all four arms, and at week 4, 64 of the 66 patients had less than $25 \mathrm{IU} / \mathrm{mL}$ of HCV RNA. At the end of treatment, the rate of undetectable HCV RNA was $94 \%, 100 \%, 94 \%$, and $94 \%$ in groups 1,2 , 3 , and 4, respectively. The corresponding figures for SVR12 rates were $94 \%, 94 \%, 94 \%$, and $89 \%$. There were only three virological failures, comprising two breakthroughs (one in group 3, and one in group 4) and one relapse (in group 4). ${ }^{82}$ The most common adverse events were headache, asthenia, diarrhea, and nausea. No grade 3-4 aminotransferase or bilirubin elevation occurred. ${ }^{82}$

Based on these excellent results, a randomized Phase $\mathrm{IIb}$ trial evaluated the combination of daclatasvir $30 \mathrm{mg}$ twice daily, asunaprevir $200 \mathrm{mg}$ twice daily, and BMS-791325 $75 \mathrm{mg}$ or $150 \mathrm{mg}$ twice daily for 12 weeks in $166 \mathrm{HCV}$ treatment-naïve patients with genotype $1 .{ }^{83}$ The median age was 54 years, $33 \%$ of patients had IL28B CC polymorphism, and $18 \%$ of patients had liver cirrhosis. These characteristics were well balanced across the two groups. On intention-to-treat analysis, SVR12 was achieved by $88.8 \%$ of patients in the BMS-791325 $75 \mathrm{mg}$ arm and by $89.5 \%$ of those in the BMS-791325 $150 \mathrm{mg}$ arm. 
Virological failures occurred in $7.5 \%$ and $5.8 \%$ of patients in the BMS-791325 $75 \mathrm{mg}$ and $150 \mathrm{mg}$ arm, respectively. Notably, all cases of virological failure occurred in patients with HCV subtype 1a. ${ }^{83}$ Overall, three adverse events occurred, and in two $(1.1 \%)$ cases led to treatment discontinuation. The most common adverse events were headache, diarrhea, fatigue, and nausea. Grade 3-4 aspartate transaminase elevation occurred in one patient $(0.5 \%)$ and a grade $3-4$ bilirubin increase in one patient $(0.5 \%) .{ }^{83}$

\section{Resistant strains}

An in vitro study identified R155K, D168G, and I170T as the primary NS3 substitutions for HCV subtype 1a associated with asunaprevir exposure. ${ }^{84}$ These substitutions conferred a low-to-moderate increase in the $\mathrm{EC}_{50}$ for asunaprevir (5-21-fold) and were associated with low levels of replications (fitness between $2 \%$ and $12 \%$ ). The double mutations Q80K plus D168V and Q80K plus D168E were associated with a large increase in $\mathrm{EC}_{50}$ (713-fold and 242 -fold, respectively) and with a good fitness (46\% and $127 \%$, respectively). ${ }^{84}$ The $\mathrm{D} 168 \mathrm{G} / \mathrm{V} / \mathrm{H} / \mathrm{Y}$ mutations were frequently detected in a subtype $1 \mathrm{~b}$-based replicon, while Q80R was rarely found. However, the D168G/V/H/Y mutations were associated with a moderate-to-large increase in $\mathrm{EC}_{50}$ (ranging between 16-fold and 280-fold) and with a low fitness (ranging from $2 \%$ to $29 \%$ ), while Q80R caused a four-fold increase in $\mathrm{EC}_{50}$ and had a high fitness (102\%). ${ }^{84}$ The same study examined serum samples collected during an asunaprevir monotherapy study. Baseline analysis frequently revealed a polymorphism in the NS3 region. The most frequent polymorphism detected at baseline was Q80K, which was identified in ten of 25 patients. This mutation was associated in vitro with low-level resistance (an increase in $\mathrm{EC}_{50}$ of 6.5-fold) but with a high fitness (139\%). In fact, in the single-dose study, patients with the K80 polymorphism had a lower viral decline than those with the Q80 polymorphism (1.29 $\log \mathrm{IU} / \mathrm{mL}$ versus $2.88 \log \mathrm{IU} / \mathrm{mL}$, respectively). This difference did not occur in the multiple-dose group. Treatment-related changes in the NS3 sequence were found in two patients, but these did not affect their viral response. Finally, asunaprevir-resistant strains did not exhibit crossresistance with NS5A inhibitors. ${ }^{84}$

A resistance analysis assessed the role of mutants in 21 patients who received the daclatasvir and asunaprevir combination alone (group $\mathrm{A}, \mathrm{n}=11$ ) or with $\mathrm{PR}$ (group B, n=10). ${ }^{77,85}$ In group A, seven patients (all with $\mathrm{HCV}$ subtype 1a) had a virological failure (six breakthroughs and one relapse). All these patients carried resistance-associated variants to NS3 inhibitors (Q80K/L, D168A/Y/E/V, or R155) and to NS5A inhibitors (Q30E/R, Y93N/C, or L31V/M). ${ }^{85}$ No patient in group $\mathrm{B}$ had a virological failure. Interestingly, five of the eleven patients in group A had baseline mutations conferring resistance to NS3 (four cases of Q80K/L and one case of $\mathrm{R} 155 \mathrm{~K})$. Three of four patients with the $\mathrm{Q} 80 \mathrm{~K} / \mathrm{L}$ polymorphism at baseline subsequently had a breakthrough during treatment, while the fourth patient achieved an SVR. The patient carrying mutation $\mathrm{R} 155 \mathrm{~K}$ relapsed during treatment. Finally, 48 weeks after treatment completion, NS5A resistance variants persisted, but not NS3 variants, suggesting a lower fitness of the latter. ${ }^{85}$ Similar results were obtained in a Japanese study in which seven cases of virological failure (three breakthroughs and four relapses), which occurred in a cohort of 43 patients treated with daclatasvir and asunaprevir, were associated with variants conferring resistance to NS3 inhibitors (D168 A/V/D) and to NS5 inhibitors (L31M/V, Y93H, Q54Y, or P58L/A). ${ }^{79,86}$ A resistance analysis of the Phase III study from Japan revealed similar results. ${ }^{80,87}$ In fact, cases of virological failure were associated with appearance of mutations conferring resistance to asunaprevir (mainly D168A/E/N/T/V/Y) and to daclatasvir (mainly L31M/V/I or Y93H/N) ${ }^{87}$

Finally, in a Phase IIb trial that evaluated triple oral treatment with asunaprevir, daclatasvir, and BMS-791325, cases of virological failure (all in patients with $\mathrm{HCV}$ subtype 1a) were associated with mutations in the NS3 region (V36M, T54A, or R155K), NS5A region (M28T, Q30E/H/R, $\mathrm{L} 31 \mathrm{M}$, or $\mathrm{Y} 93 \mathrm{H} / \mathrm{N})$, and $\mathrm{NS} 5 \mathrm{~B}$ region $(\mathrm{P} 495 \mathrm{~L} / \mathrm{S}){ }^{83}$

\section{Conclusion}

Treatment of chronic HCV infection is undergoing a revolution. Interferon-based combinations, which had been the only treatment available for about 25 years, will be replaced by interferon-free therapies. Interferon-based treatments are poorly tolerated and the adverse events associated with these combinations are sometimes severe. ${ }^{88-93}$ In contrast, interferon-free therapies have the great advantages of high tolerability and safety, and could thus be used even in advanced stages of liver disease (eg, in decompensated cirrhosis) or in cases of significant comorbidities. Moreover, the efficacy of interferon-free combinations is in several cases outstanding, and notably, is high even in patients who did not respond to interferon-based treatments. Therefore, considering also the large number of highly effective drugs, HCV infection will probably become a curable disease in nearly all cases. The only problem with these new therapies is their cost, which will be high, at least when they first come onto 
the market. In this light, low-resource countries may have difficulty in accessing these combinations. Moreover, given that the disease is asymptomatic during most of its natural history, screening programs are required to diagnose and treat the infection at a nonadvanced stage. Few data are available for patients who are treated in advanced decompensated stages, and the efficacy of the drugs in terms of increasing quality of life and survival has yet to be demonstrated. It is feasible that HCV eradication will be associated with an improved prognosis, even in patients with decompensated disease, as occurs for hepatitis B virus-related liver diseases, but this remains to be demonstrated. ${ }^{94}$

Based on the data presented, asunaprevir is a good protease inhibitor that decreases $\mathrm{HCV}$ replication activity to a large extent, and has an optimal rate of viral clearance if given in association with the NS5A inhibitor daclatasvir in HCV subtype $1 \mathrm{~b}$ patients, regardless of their response to previous interferon-based treatment. In contrast, patients with HCV subtype 1a respond poorly to this combination and need a quadruple strategy (asunaprevir, daclatasvir, and PR) to obtain a high rate of viral clearance. The drawback of asunaprevir (and of all protease inhibitors) is its low barrier to resistance. However, its combination with an antiviral agent that has a different mechanism of action (ie, daclatasvir) overcomes this issue, as shown by the low rate of virological failure due to resistance, especially in patients with HCV.

The tolerability of asunaprevir is quite good. The major tolerability and safety issue is the increase in aminotransferase levels, which in some cases is accompanied by an increase in bilirubin. This elevation is mild in most cases, and is not associated with clinical decompensation. It should be noted that due to the hepatotoxicity of the drug, asunaprevir doses were reduced during its clinical development. In fact, the dosage of $600 \mathrm{mg}$ twice daily in the initial studies were lowered to $200 \mathrm{mg}$ twice daily in most of the Phase II studies and to $100 \mathrm{mg}$ twice daily in the two available Phase III trials. Based on the reassuring results of the most recent trials, we believe that hepatotoxicity does not represent a major obstacle to administration of asunaprevir. However, due to this potential risk of hepatic flare and to the highly impaired pharmacokinetics in patients with decompensated disease, it is unlikely that asunaprevir can be considered for patients in a decompensated phase of the disease. Moreover, although asunaprevir has been demonstrated in vitro to be effective against strains other than genotype 1 (namely genotypes 4,5 , and 6 ), only a few patients with genotype 4 have received asunaprevir, and no patients with genotype 5 or 6 .
Finally, an often overlooked aspect is the safety and efficacy of these new drugs during pregnancy. To our knowledge, no study has yet assessed this issue in HCV infection, unlike in hepatitis B virus infection. ${ }^{95,96}$

In conclusion, thanks to its robust antiviral activity and good tolerability, asunaprevir is an excellent protease inhibitor to use in combination with drugs that exert their effect through other mechanisms. The limits of this drug are the risk of increased liver enzymes, impaired pharmacokinetics in patients with decompensated disease, and a low barrier to resistance. For these reasons, its use in patient with ChildPugh class B or C cirrhosis is unlikely. The most frequently studied asunaprevir combination (with the NS5A inhibitor daclatasvir) results in an excellent rate of viral clearance in patients with subtype $1 \mathrm{~b}$ infection. Therefore, patients with chronic HCV subtype $1 \mathrm{~b}$ hepatitis or compensated cirrhosis will probably benefit from this combination in the near future.

\section{Acknowledgment}

The authors are grateful to Jean Ann Gilder (Scientific Communication srl, Naples, Italy) for text editing.

\section{Disclosure}

The authors report no conflicts of interest in this work.

\section{References}

1. World Health Organization. Hepatitis C. Fact sheet 164. 2013. Available from: http://www.who.int/mediacentre/factsheets/fs164/en/index.html. Accessed January 17, 2014.

2. Sagnelli E, Stroffolini T, Mele A, et al. The importance of HCV on the burden of chronic liver disease in Italy: a multicenter prevalence study of 9,997 cases. J Med Virol. 2005;75(4):522-527.

3. Petruzziello A, Coppola N, Diodato AM, et al. Age and gender distribution of hepatitis $\mathrm{C}$ virus genotypes in the metropolitan area of Naples. Intervirology. 2013;56(3):206-212.

4. Guadagnino V, Stroffolini T, Rapicetta M, et al. Prevalence, risk factors, and genotype distribution of hepatitis $\mathrm{C}$ virus infection in the general population: a community-based survey in southern Italy. Hepatology. 1997;26(4):1006-1011.

5. Maasoumy B, Wedemeyer H. Natural history of acute and chronic hepatitis C. Best Pract Res Clin Gastroenterol. 2012;26(4): 401-412.

6. Filippini P, Coppola N, Scolastico C, et al. Does HIV infection favor the sexual transmission of hepatitis C? Sex Transm Dis. 2001;28(12): 725-729

7. Gentile I, De Stefano A, Di Flumeri G, et al. Concomitant interferon-alpha and chemotherapy in hepatitis $\mathrm{C}$ and colorectal cancer: a case report. In Vivo. 2013;27(4):527-529.

8. Gentile I, Di Flumeri G, Scarica S, et al. Acute hepatitis C in patients undergoing hemodialysis: experience with high-dose interferon therapy. Minerva Urol Nefrol. 2013;65(1):83-84.

9. Mele A, Spada E, Sagliocca L, et al. Risk of parenterally transmitted hepatitis following exposure to surgery or other invasive procedures: results from the hepatitis surveillance system in Italy. $J$ Hepatol. 2001;35(2):284-289. 
10. Carney K, Dhalla S, Aytaman A, Tenner CT, Francois F. Association of tattooing and hepatitis $\mathrm{C}$ virus infection: a multicenter case-control study. Hepatology. 2013;57(6):2117-2123.

11. Coppola N, Pisapia R, Tonziello G, et al. Improvement in the aetiological diagnosis of acute hepatitis $\mathrm{C}$ : a diagnostic protocol based on the anti-HCV-IgM titre and IgG Avidity Index. J Clin Virol. 2009;46(3):222-229.

12. Coppola N, Pisapia R, Marrocco C, et al. Anti-HCV IgG avidity index in acute hepatitis C. J Clin Virol. 2007;40(2):110-115.

13. Gentile I, Coppola N, Pasquale G, et al. A simple noninvasive score based on routine parameters can predict liver cirrhosis in patients with chronic Hepatitis C. Hepat Mon. 2013;13(5):e8352.

14. Hoofnagle JH. Hepatitis C: the clinical spectrum of disease. Hepatology. 1997;26(3 Suppl 1):15S-20S.

15. Fortunato G, Castaldo G, Oriani G, et al. Multivariate discriminant function based on six biochemical markers in blood can predict the cirrhotic evolution of chronic hepatitis. Clin Chem. 2001;47(9): $1696-1700$.

16. Fortunato G, Calcagno G, Bresciamorra V, et al. Multiple sclerosis and hepatitis $\mathrm{C}$ virus infection are associated with single nucleotide polymorphisms in interferon pathway genes. J Interferon Cytokine Res. 2008;28(3):141-152.

17. Gentile I, Buonomo AR, Zappulo E, Borgia G. Is it possible to predict HCV-related liver cirrhosis non-invasively through routine laboratory parameters? Infez Med. 2014;22(1):11-18.

18. Gentile I, Meola M, Buonomo AR, et al. Human platelet antigen-3 genotype predicts platelet count in patients with $\mathrm{HCV}$ infection. In Vivo. 2013;27(6):773-777.

19. Sagnelli E, Pisaturo M, Stanzione M, et al. Presentation, outcomes, and response to therapy among patients with acute exacerbation of chronic hepatitis C. Clin Gastroenterol Hepatol. 2013;13(13):00466-00467.

20. Coppola N, Gentile I, Pasquale G, et al. Anti-HBc positivity was associated with histological cirrhosis in patients with chronic hepatitis C. Ann Hepatol. 2014;13(1):20-26.

21. Gentile I, Viola C, Graf M, et al. A simple noninvasive score predicts gastroesophageal varices in patients with chronic viral hepatitis. J Clin Gastroenterol. 2009;43(1):81-87.

22. Sagnelli C, Uberti-Foppa C, Pasquale G, et al. Factors influencing liver fibrosis and necroinflammation in HIV/HCV coinfection and HCV monoinfection. Infection. 2013;41(5):959-967.

23. Ferrari SM, Fallahi P, Mancusi C, et al. HCV-related autoimmune disorders in HCV chronic infection. Clin Ter. 2013;164(4):e305-e312.

24. Coppola N, Pisaturo M, Guastafierro S, et al. Increased hepatitis C viral load and reactivation of liver disease in HCV RNA-positive patients with onco-haematological disease undergoing chemotherapy. Dig Liver Dis. 2012;44(1):49-54.

25. Zampino R, Coppola N, Cirillo G, et al. Abdominal fat interacts with PNPLA3 I148M, but not with the APOC3 variant in the pathogenesis of liver steatosis in chronic hepatitis C. J Viral Hep. 2013;20(8): 517-523.

26. Coppola N, Pascalis SD, Pisaturo M, et al. Sustained virological response to antiviral treatment in chronic hepatitis $\mathrm{C}$ patients may be predictable by HCV RNA clearance in peripheral blood mononuclear cells. J Clin Virol. 2013;58(4):748-750.

27. Fusco F, D’Anzeo G, Rossi A, et al. Erectile dysfunction in patients with chronic viral hepatitis: a systematic review of the literature. Expert Opin Pharmacother. 2013;14(18):2533-2544.

28. Braks RE, Ganne-Carrie N, Fontaine H, et al. Effect of sustained virological response on long-term clinical outcome in 113 patients with compensated hepatitis C-related cirrhosis treated by interferon alpha and ribavirin. World J Gastroenterol. 2007;13(42):5648-5653.

29. Bruno S, Stroffolini T, Colombo M, et al. Sustained virological response to interferon-alpha is associated with improved outcome in HCV-related cirrhosis: a retrospective study. Hepatology. 2007;45(3):579-587.

30. Di Marco V, Almasio PL, Ferraro D, et al. Peg-interferon alone or combined with ribavirin in $\mathrm{HCV}$ cirrhosis with portal hypertension: a randomized controlled trial. J Hepatol. 2007;47(4):484-491.
31. Gentile I, Borgia G. Surrogate endpoints and non-inferiority trials in chronic viral hepatitis. J Hepatol. 2010;52(5):778.

32. Au JS, Pockros PJ. Novel therapeutic approaches for hepatitis C. Clin Pharmacol Ther. 2014;95(1):78-88.

33. Jaroszewicz J, Flisiak R, Dusheiko G. A pill for HCV - myth or foreseeable future? Liver Int. 2014;34(1):6-11.

34. US Food and Drug Administration. Approval of Sovaldi (sofosbuvir) tablets for the treatment of chronic hepatitis C. 2013. Available from: http://www.fda.gov/forconsumers/byaudience/forpatientadvocates/ ucm377920.htm. Accessed January 17, 2014.

35. Gentile I, Borgia F, Buonomo AR, Castaldo G, Borgia G. A novel promising therapeutic option against hepatitis $C$ virus: an oral nucleotide NS5B polymerase inhibitor sofosbuvir. Curr Med Chem. 2013;20(30): 3733-3742.

36. Gentile I, Borgia F, Zappulo E, Buonomo AR, Spera AM, Castaldo G, et al. Efficacy and Safety of Sofosbuvir in Treatment of Chronic Hepatitis C: The Dawn of a New Era. Rev Recent Clin Trials. 2014;9(1):1-7.

37. Gentile I, Viola C, Borgia F, Castaldo G, Borgia G. Telaprevir: a promising protease inhibitor for the treatment of hepatitis $\mathrm{C}$ virus infection. Curr Med Chem. 2009;16(9):1115-1121.

38. Mederacke I, Wedemeyer H, Manns MP. Boceprevir, an NS3 serine protease inhibitor of hepatitis $\mathrm{C}$ virus, for the treatment of $\mathrm{HCV}$ infection. Curr Opin Investig Drugs. 2009;10(2):181-189.

39. You DM, Pockros PJ. Simeprevir for the treatment of chronic hepatitis C. Expert Opin Pharmacother. 2013;14(18):2581-2589.

40. Coppola N, Pisaturo M, Tonziello G, Sagnelli C, Sagnelli E, Angelillo IF. Efficacy of Pegylated interferon alpha-2a and alpha-2b in patients with genotype 1 chronic hepatitis C: a meta-analysis. BMC Infect Dis. 2012;12(357):1471-2334.

41. Ghany MG, Strader DB, Thomas DL, Seeff LB. Diagnosis, management, and treatment of hepatitis C: an update. Hepatology. 2009;49(4):1335-1374.

42. Morisco F, Granata R, Stroffolini T, et al. Sustained virological response: a milestone in the treatment of chronic hepatitis C. World $J$ Gastroenterol. 2013;19(18):2793-2798.

43. Ghany MG, Nelson DR, Strader DB, Thomas DL, Seeff LB. An update on treatment of genotype 1 chronic hepatitis $\mathrm{C}$ virus infection: 2011 practice guideline by the American Association for the Study of Liver Diseases. Hepatology. 2011;54(4):1433-1444.

44. Poordad F, Agarwal K, Younes Z, Cohen DE, Xie W, Podsadecki T. Low relapse rate leads to high concordance of SVR4 and SVR12 with SVR24 after treatment with ABT-450/r, ABT-267, ABT-333 + ribavirin in patients with chronic HCV genotype 1 infection in the AVIATOR study. Paper presented at the 64th Annual Meeting of the American Association for the Study of Liver Diseases, November 1-5, 2013, Washington, DC, USA.

45. Poordad F, McCone J Jr, Bacon BR, et al. Boceprevir for untreated chronic HCV genotype 1 infection. N Engl J Med. 2011;364(13): 1195-1206.

46. Jacobson IM, McHutchison JG, Dusheiko G, et al. Telaprevir for previously untreated chronic hepatitis $\mathrm{C}$ virus infection. $N$ Engl $J$ Med. 2011;364(25):2405-2416.

47. Lange CM, Bojunga J, Ramos-Lopez E, et al. Vitamin D deficiency and a CYP27B1-1260 promoter polymorphism are associated with chronic hepatitis $\mathrm{C}$ and poor response to interferon-alfa based therapy. J Hepatol. 2011;54(5):887-893.

48. Ismail MH. Prediction of sustained virologic responses to combination therapy of pegylated interferon-alpha and ribavirin in patients with chronic hepatitis C infection. J Family Community Med. 2013;20(1): 35-40.

49. Borgia G, Gentile I, Fortunato G, et al. Homocysteine levels and sustained virological response to pegylated-interferon alpha $2 \mathrm{~b}$ plus ribavirin therapy for chronic hepatitis C: a prospective study. Liver Int. 2009;29(2):248-252.

50. Distante S, Bjoro K, Hellum KB, et al. Raised serum ferritin predicts non-response to interferon and ribavirin treatment in patients with chronic hepatitis C infection. Liver. 2002;22(3):269-275. 
51. Gentile I, Viola C, Paesano L, et al. Iron depletion before HCV antiviral therapy: a pilot, randomized, controlled trial. J Clin Apher. 2009;24(5): 190-196.

52. Abu-Mouch S, Fireman Z, Jarchovsky J, Zeina AR, Assy N. Vitamin D supplementation improves sustained virologic response in chronic hepatitis C (genotype 1)-naive patients. World J Gastroenterol. 2011;17(47):5184-5190.

53. Nimer A, Mouch A. Vitamin D improves viral response in hepatitis C genotype 2-3 naive patients. World J Gastroenterol. 2012;18(8): $800-805$.

54. Coppola N, Marrone A, Pisaturo M, et al. Role of interleukin 28-B in the spontaneous and treatment-related clearance of $\mathrm{HCV}$ infection in patients with chronic HBV/HCV dual infection. Eur J Clin Microbiol Infect Dis. 2014;33(4):559-567.

55. Coppola N, Pisaturo M, Sagnelli C, Sagnelli E, Angelillo IF. Peg-interferon plus ribavirin with or without boceprevir or telaprevir for HCV genotype 1: a meta-analysis on the role of response predictors. PLoS One. 2014;9(4):e94542.

56. Gentile I, Borgia F, Coppola N, Buonomo AR, Castaldo G, Borgia G. Daclatasvir: the first of a new class of drugs targeted against hepatitis $\mathrm{C}$ virus NS5A. Curr Med Chem. 2014;21(12):1391-1404.

57. Gentile I, Buonomo AR, Borgia F, Castaldo G, Borgia G. Ledipasvir: a novel synthetic antiviral for the treatment of HCV infection. Expert Opin Investig Drugs. 2014;23(4):561-571.

58. Asselah T. ABT-450 combined with ritonavir, in addition to ABT-333 and ribavirin: a race for an interferon-free regimen to cure $\mathrm{HCV}$ infection. J Hepatol. 2013;59(4):885-888.

59. Stedman CA. Current prospects for interferon-free treatment of hepatitis C in 2012. J Gastroenterol Hepatol. 2013;28(1):38-45.

60. Sarrazin C, Hezode C, Zeuzem S, Pawlotsky JM. Antiviral strategies in hepatitis C virus infection. J Hepatol. 2012;56(1):S88-S100.

61. Gentile I, Buonomo AR, Borgia F, Zappulo E, Castaldo G, Borgia G. MK-5172: a second-generation protease inhibitor for the treatment of hepatitis C virus infection. Expert Opin Investig Drugs. 2014;23(5):719-728.

62. Gentile I, Coppola N, Buonomo AR, Zappulo E, Borgia G. Investigational nucleoside and nucleotide polymerase inhibitors and their use in treating hepatitis C virus. Expert Opin Investig Drugs. 2014:1-13.

63. Gentile I, Buonomo AR, Zappulo E, Borgia G. Interferon-free therapies for chronic hepatitis $\mathrm{C}$ : toward a hepatitis $\mathrm{C}$ virus-free world? Expert Rev Anti Infect Ther. 2014;12(7):763-773.

64. Gentile I, Carleo MA, Borgia F, Castaldo G, Borgia G. The efficacy and safety of telaprevir - a new protease inhibitor against hepatitis $\mathrm{C}$ virus. Expert Opin Investig Drugs. 2010;19(1):151-159.

65. Yan Y, Li Y, Munshi S, et al. Complex of NS3 protease and NS4A peptide of BK strain hepatitis $\mathrm{C}$ virus: a 2.2 A resolution structure in a hexagonal crystal form. Protein Sci. 1998;7(4):837-847.

66. Germain MA, Chatel-Chaix L, Gagne B, et al. Elucidating novel hepatitis $\mathrm{C}$ virus/host interactions using combined mass spectrometry and functional genomics approaches. Mol Cell Proteomics. 2014;13(1):184-203.

67. McPhee F, Sheaffer AK, Friborg J, et al. Preclinical profile and characterization of the hepatitis $\mathrm{C}$ virus NS3 protease inhibitor asunaprevir (BMS-650032). Antimicrob Agents Chemother. 2012;56(10): 5387-5396.

68. Friborg J, Levine S, Chen C, et al. Combinations of lambda interferon with direct-acting antiviral agents are highly efficient in suppressing hepatitis C virus replication. Antimicrob Agents Chemother. 2013;57(3): 1312-1322.

69. Pasquinelli C, Eley T, Villegas C, et al. Safety, tolerability, pharmacokinetics and antiviral activity following single- and multipledose administration of BMS-650032, a novel HCV NS3 inhibitor, in subjects with chronic genotype $1 \mathrm{HCV}$ infection. Hepatology. 2009;50(4):411A-412A

70. Eley T, He B, Chang I, et al. The effect of hepatic impairment on the pharmacokinetics of asunaprevir, an HCV NS3 protease inhibitor. Antivir Ther. April 7, 2014. [Epub ahead of print.]
71. Garimella T, He B, Luo W-L, et al. Asunaprevir pharmacokinetics and safety in subjects with impaired renal function. Hepatology. 2013;58: 430A.

72. Garimella T, Adamczyk R, Hu P, et al. No clinically relevant interactions between asunaprevir and selective serotonin reuptake inhibitors (escitalopram and sertraline) in healthy subjects. Hepatology. 2013;58:445A-446A.

73. Pasquinelli C, McPhee F, Eley T, et al. Single- and multiple-ascendingdose studies of the NS3 protease inhibitor asunaprevir in subjects with or without chronic hepatitis C. Antimicrob Agents Chemother. 2012;56(4): 1838-1844.

74. Bronowicki JP, Pol S, Thuluvath PJ, et al. Randomized study of asunaprevir plus pegylated interferon-alpha and ribavirin for previously untreated genotype 1 chronic hepatitis C. Antivir Ther. 2013;18(7):885-893.

75. Bronowicki JP, Ratziu V, Gadano A, et al. Asunaprevir with Peginterferon-alfa and ribavirin in treatment-naive patients with genotype-1 or-4 chronic hepatitis C: SVR24 results from a randomized phase 2b study (AI447016). J Hepatol. 2013;58:S571-S572.

76. Vierling JM, Lataillade M, Gane EJ, et al. Sustained virologic response (SVR12) in HCV genotype 1 patients receiving peginterferon lambda in combination with ribavirin and either daclatasvir or asunaprevir: interim results from the D-LITE study. Hepatology. 2012;56(6): $1522-1523$

77. Lok AS, Gardiner DF, Lawitz E, et al. Preliminary study of two antiviral agents for hepatitis C genotype 1. N Engl J Med. 2012;366(3): 216-224.

78. Lok AS, Gardiner DF, Hezode C, et al. Randomized trial of daclatasvir and asunaprevir with or without PegIFN/RBV for hepatitis C virus genotype 1 null responders. J Hepatol. 2014;60(3):490-499.

79. Suzuki Y, Ikeda K, Suzuki F, et al. Dual oral therapy with daclatasvir and asunaprevir for patients with HCV genotype $1 \mathrm{~b}$ infection and limited treatment options. J Hepatol. 2013;58(4):655-662.

80. Kumada H, Suzuki Y, Ikeda K, et al. Daclatasvir plus asunaprevir for chronic HCV genotype 1b infection. Hepatology. 2014;59(6): 2083-2091.

81. Manns M, Pol S, Jacobson I. All-oral dual therapy with daclatasvir and asunaprevir in patients with HCV genotype 1B infection: phase 3 study results. J Hepatol. 2014;60(1):S524-S525.

82. Everson GT, Sims KD, Rodriguez-Torres M, et al. Efficacy of an interferon- and ribavirin-free regimen of daclatasvir, asunaprevir, and BMS-791325 in treatment-naive patients with HCV genotype 1 infection. Gastroenterology. 2014;146(2):420-429.

83. Everson GT, Sims KD, Thuluvath PJ, et al. Phase $2 b$ study of the interferon-free and ribavirin-free combination of daclatasvir, asunaprevir, and BMS-791325 for 12 weeks in treatment-naive patients with chronic HCV genotype 1 infection. Hepatology. 2013;58(6): 1377A.

84. McPhee F, Friborg J, Levine S, et al. Resistance analysis of the hepatitis C virus NS3 protease inhibitor asunaprevir. Antimicrob Agents Chemother. 2012;56(7):3670-3681.

85. McPhee F, Hernandez D, Yu F, et al. Resistance analysis of hepatitis C virus genotype 1 prior treatment null responders receiving daclatasvir and asunaprevir. Hepatology. 2013;58(3):902-911.

86. Karino Y, Toyota J, Ikeda K, et al. Characterization of virologic escape in hepatitis $\mathrm{C}$ virus genotype $1 \mathrm{~b}$ patients treated with the direct-acting antivirals daclatasvir and asunaprevir. J Hepatol. 2013;58(4):646-654.

87. McPhee F, Toyota J, Chayama K, et al. Analysis of HCV resistance variants in a Phase 3 trial of daclatasvir combined with asunaprevir for Japanese patients with genotype $1 \mathrm{~b}$ infection. Hepatology. 2013;58:749A.

88. Borgia G, Reynaud L, Gentile I, et al. Pernicious anemia during IFNalpha treatment for chronic hepatitis C. J Interferon Cytokine Res. 2003;23(1):11-12.

89. Borgia G, Reynaud L, Gentile I, et al. Myasthenia gravis during lowdose IFN-alpha therapy for chronic hepatitis C. J Interferon Cytokine Res. 2001;21(7):469-470. 
90. Gentile I, Viola C, Reynaud L, et al. Hemolytic anemia during pegylated IFN-alpha2b plus ribavirin treatment for chronic hepatitis $\mathrm{C}$ : ribavirin is not always the culprit. $J$ Interferon Cytokine Res. 2005;25(5):283-285.

91. Tosone G, Borgia G, Gentile I, et al. A case of pegylated interferon alpha-related diabetic ketoacidosis: can this complication be avoided? Acta Diabetol. 2007;44(3):167-169.

92. Hezode C, Fontaine H, Dorival C, et al. Triple therapy in treatmentexperienced patients with $\mathrm{HCV}$-cirrhosis in a multicentre cohort of the French Early Access Programme (ANRS CO20-CUPIC) NCT01514890. J Hepatol. 2013;59(3):434-441.
93. D'Ambrosio R, Colombo M. Safety of direct antiviral agents in real life. Dig Liver Dis. 2013;45 Suppl 5:S363-S366.

94. Borgia G, Gentile I. Treating chronic hepatitis B: today and tomorrow. Curr Med Chem. 2006;13(23):2839-2855.

95. Borgia G, Carleo MA, Gaeta GB, Gentile I. Hepatitis B in pregnancy. World J Gastroenterol. 2012;18(34):4677-4683.

96. Gentile I, Zappulo E, Buonomo AR, Borgia G. Prevention of motherto-child transmission of HBV and HCV. Expert Rev Anti Infect Ther. May 20, 2014. [Epub ahead of print.]

\section{Publish your work in this journal}

Therapeutics and Clinical Risk Management is an international, peerreviewed journal of clinical therapeutics and risk management, focusing on concise rapid reporting of clinical studies in all therapeutic areas, outcomes, safety, and programs for the effective, safe, and sustained use of medicines. This journal is indexed on PubMed Central, CAS,
EMBase, Scopus and the Elsevier Bibliographic databases. The manuscript management system is completely online and includes a very quick and fair peer-review system, which is all easy to use. Visit http://www.dovepress.com/testimonials.php to read real quotes from published authors.

Submit your manuscript here: http://www.dovepress.com/therapeutics-and-clinical-risk-management-journal 